\title{
Incidencia de los virus de inmudeficiencia y leucemia en Felis catus en la Clínica Veterinaria Gattos Tunja-Boyacá
}

\author{
Incidence of immunodeficiency and leukemia viruses in \\ Felis catus in the Veterinary Clinic Gattos Tunja-Boyacá
}

\author{
Delia Yuliana Massey Malagón ${ }^{a^{*}}$ \\ Sandra Rocío Cuervo Saavedra ${ }^{b}$ \\ Mayer Isnardo Lagos López ${ }^{c}$
}

Fecha de Recepción: 08.09.2018

Fecha de Aceptación: 06.11.2018

DOI: https://doi.org/10.19053/01217488.v10.n1.2019.8402

\begin{abstract}
Resumen
Leucemia felina (FeLV) e inmunodeficiencia (FIV) son enfermedades inmunodefiecientes muy complejas y falta conocer totalmente las causas que las generan. Son infecciones persistentes, con alteraciones o desequilibrios en el sistema inmune. Se puede observar el aumento de la población felina a nivel mundial y en Colombia, al igual que en la ciudad de Tunja, por tanto, las enfermedades infecciosas como las nombradas anteriormente, también prevalecen, y en consecuencia, se necesitan diagnosticar, sin embargo, en Colombia, hay pocos estudios que permitan conocer la prevalencia de Leucemia e Inmunodeficiencia o se subestima su diagnóstico. Con la realización de esta investigación se busca, establecer la incidencia de los virus de inmunodeficiencia y leucemia felina en la población de gatos en la ciudad de Tunja, estudio, realizado con felinos (escogidos por conveniencia), independientes de raza o sexo, no sintomáticos, con franja etaria a partir de siete meses de edad (estimada por el análisis de arcada dentaria), que sean recibidos durante un periodo de seis meses en la clínica veterinaria Gattos. Por la fácil transmisión de leucemia, es importante la prevención del contagio a través del aislamiento de animales enfermos y la vacunación de animales sanos, para el caso de inmunodeficiencia, evitar peleas entre gatos sanos y enfermos. En el presente estudio se halló una incidencia de 17\% tanto para el virus de leucemia como de inmunodeficiencia.
\end{abstract}

Palabras claves: Diagnóstico, epidemiología, gammaretrovirus, inmunodeficiencia, leucemia.

a M.Sc (e). Maestría en Ciencias Veterinarias, Facultad de Ciencias Agrarias, Universidad Pedagógica y Tecnológica de Colombia.

b M.Sc (e). Maestría en Ciencias, Facultad de Ciencias Agrarias, Universidad Pedagógica y Tecnológica de Colombia.

c M.Sc (e). Maestría en Ciencias Biológicas, Facultad de Ciencias, Grupo de Investigación Biología para la Conservación, Universidad Pedagógica y Tecnológica de Colombia.

* Autor de correspondencia: delia.massey@uptc.edu.co; yuliana30060@gmail.com 


\begin{abstract}
Feline leukemia (FeLV) and immunodeficiency (FIV) are very complex diseases and are not yet fully known. They are persistent infections, with alterations or imbalances in the immune system. The increase in feline population worldwide and in Colombia can be observed, as in the city of Tunja, therefore, infectious diseases such as those mentioned above, also prevail, and as a consequence, need to be diagnosed, however, in Colombia, there are few studies that allow to know the prevalence of Leukemia and Immunodeficiency or its diagnosis is underestimated, with the realization of this research is sought, to establish the incidence of the immunodeficiency and feline leukemia viruses in the population of cats in the city of Tunja, study, carried out with cats (chosen for convenience), independent of race or sex, non-symptomatic, with age range from seven months of age (estimated by the analysis of dental arch), which are received during a period of six months at the veterinary clinic Gattos. Because of the easy transmission of leukemia, it is important to prevent infection through the isolation of sick animals and the vaccination of healthy animals, in the case of immunodeficiency, to avoid fights between healthy and sick cats. In the present study we found an incidence of $17 \%$ for both the leukemia virus and the immunodeficiency virus.
\end{abstract}

Key words: Diagnosis, epidemiology, gammaretrovirus, immunodeficiency, leukemia.

\section{INTRODUCCIÓN}

Es importante definir y verificar como es el desarrollo del virus de la leucemia felina (FeLV), ya que es un retrovirus del género Gammaretrovirus, este virus afecta a todos los gatos domésticos en el mundo, al igual que gatos silvestres [1]. Los retrovirus generan en gatos domésticos y otros felinos una infección persistente. La transmisión de retrovirus patógenos es principalmente de lentivirus, virus inmunodeficiencia felina (FIV), virus oncogénico, y virus de leucemia felina (FeLV). Estos virus, poseen una amplia distribución. Los lentivirus, FIV, infectan aproximadamente el 5\% de los gatos sanos. En la población general de gatos sanos, FeLV tiene una prevalencia del $1 \%$, aunque en familias en que el virus es enzoótico la prevalencia es comúnmente del $30-40 \%$ [2].

El FeLV, fue descrito por primera vez por William Jarret en 1964 [2], cuando se observó mediante microscopía electrónica la presencia de partículas virales en la membrana de células tumorales de un gato con linfosarcoma [3], lo que demostró que el virus puede ser transmitido y causar la misma enfermedad cuando es inyectado de forma experimental en gatos saludables [4], confirmándose así que la presencia viral es el factor necesario para el desarrollo de la neoplasia linfocítica en felinos [5]. La infección con FeLV en gatos domésticos existe en todo el mundo y varía entre 1 y $8 \%$ en gatos saludables. Se han reportado frecuencias de infección hasta de $21 \%$ en gatos que presentan otras enfermedades [6].
El virus de la Inmunodeficiencia Felina (FIV), genera una enfermedad vírica que provoca en el gato afectado un cuadro parecido al que produce el virus del SIDA humano. Se transmite, principalmente por mordedura de un gato infectado a otro sano. El contacto no agresivo, casual, entre gatos que conviven en un mismo entorno, aunque compartan bebederos, comederos, juguetes y otros enseres personales, no parece ser una vía de contagio de este virus [30]. En raras ocasiones, la enfermedad se transmite durante la gestación cuando la madre es portadora del virus, o bien al atravesar el canal del parto o cuando los gatitos recién nacidos comienzan a mamar leche infectada [29].

No existe tratamiento curativo para este virus y actualmente no existe ninguna vacuna. Los gatos infectados con el FIV pueden vivir mucho tiempo, pero requieren revisiones y controles periódicos y medidas especiales de atención por parte de propietarios y veterinarios. La mejor manera de evitar la infección es mantener a los gatos protegidos de los factores de riesgo [7]. La castración, para reducir la agresividad y, por tanto, las mordeduras y evitar los contactos con gatos no controlados que pueden ser portadores de este virus y de otras enfermedades son buenas vías para impedir el contagio.

Por otra parte, FeLV es un virus de distribución mundial [30]. Produce una serie de enfermedades muy graves en el gato que se relacionan con problemas del sistema inmunitario y con la formación de tumores. El virus de la leucemia 
felina, se transmite fundamentalmente por la saliva y puede contagiarse a través de secreciones nasales de gatos infectados, al lavarse o compartir platos de agua o comida y por mordedura [31]. El contagio será posible siempre que exista un contacto directo y estrecho entre gatos. También puede ocurrir la transmisión de la madre a los cachorros, a través de la placenta o durante la lactación [30].

La infección por FeLV va a ser muy distinta en cada gato, va a estar muy influenciada por la respuesta inmune que tiene el gato al virus, por la edad del animal (los gatos jóvenes son más propensos a infectarse) o por la cantidad de virus y tiempo al que se ha estado expuesto [8]. Los signos clínicos son muchos y muy variados ya que pueden aparecer síntomas debidos directamente al virus o por infecciones oportunistas que producen alteraciones del sistema inmune. Puede aparecer pérdida de apetito, adelgazamiento, problemas dentales o de encías, alteraciones respiratorias, alteraciones nerviosas, alteraciones oculares. Se pueden administrar terapias de soporte e intentar tratar las enfermedades que aparecen como consecuencia del debilitamiento del gato aunque cada gato debe valorarse individualmente según su cuadro clínico y condiciones, sin embargo para la leucemia felina es una enfermedad que es posible vacunar [7].

Los FeLV y de la FIV son retrovirus con un impacto global sobre la salud del gato doméstico (Felis catus). Los dos virus difieren en su potencial para causar enfermedad. El FeLV es más patogénico y ha sido ampliamente considerado responsable de la mayoría de los síndromes clínicos más que cualquier otro agente infeccioso en gatos [9]. La infección con FeLV en gatos domésticos existe en todo el mundo y varía entre 1 y $8 \%$ en gatos saludables. Se han reportado frecuencias de infección hasta de $21 \%$ en gatos que presentan otras enfermedades [6]. Afecta en igual proporción a hembras y machos $[10 ; 11]$. Los hallazgos más comunes debido a la viremia persistente de FeLV son: inmunosupresión, anemia y linfoma [12]. La prevalencia es mucho mayor en gatos que van al exterior y en gatos sociables, ya que el virus requiere un contacto directo para una transmisión eficaz [6].
Este estudio tiene como objetivo realizar la descripción epidemiológica de los gatos positivos para FeLV y FIV, diagnosticados en la clínica veterinaria Gattos en la ciudad de TunjaBoyacá, en el período comprendido entre Julio a Diciembre del 2017.

\section{MATERIALES Y MÉTODOS}

La presente investigación es de tipo descriptiva, prospectiva y aleatorizada, realizada con felinos (escogidos por conveniencia), independientes de raza o sexo, no sintomáticos, a los que los propietarios buscaban, descartar estas enfermedades, con franja etaria a partir de siete meses de edad (estimada por el análisis de arcada dentaria), que fueron recibidos durante seis meses en el periodo comprendido entre julio a diciembre de 2017, en la clínica veterinaria Gattos de la ciudad de Tunja, no importando su procedencia.

\subsection{Tipo y área de estudio}

Se realizó un estudio descriptivo que incluyó 100 gatos domésticos, a los cuales se les realizó el examen de leucemia e inmunodeficiencia en un período de seis meses. El estudio se llevó a cabo en la ciudad de Tunja-Boyacá, situada a 2810 msnm con una temperatura media anual de $15^{\circ} \mathrm{C}$, en la clínica veterinaria Gattos.

\subsection{Tamaño de la muestra}

Se tuvieron en cuenta los animales mayores de 7 meses (hembras y machos) que acudieron en un tiempo determinado a la toma de sangre sin presentar algún signo clínico, se estableció un intervalo de confianza del $99 \%$ y un error máximo permisible del $1 \%$. Teniendo en cuenta lo anterior, el tamaño de la muestra fue de 100 gatos.

\subsection{Criterios de exclusión}

Se excluyeron todos los felinos menores de 7 meses y mayores de 5 años, animales enfermos y animales con vacuna de Leucemia Viral Felina.

\subsection{Procedimiento}

En el período comprendido entre julio y diciembre del 2017, se realizó la toma de muestras 
de sangre a los gatos de estudio, a cada animal se le extrajo $1 \mathrm{ml}$ de sangre a través de la punción de la vena cefálica. A ningún animal se le realizó sedación. Las muestras donde se evidenció signos de hemólisis, fueron descartadas debido al riesgo de falsos positivos/negativos.

Las muestras, fueron enviadas y procesadas en el laboratorio Animal lab de la ciudad de Sogamoso. Para el diagnóstico simultáneo de leucemia e inmunodeficiencia felina se utilizó el kit comercial SNAP combo FeLV Ag/ FIV $\mathrm{Ab}$ (Laboratories Idexx, Toronto, Canadá). Adicionalmente se usó el test de Elisa para la detección simultánea de antígenos de virus de leucemia felina (p27) y para anticuerpos específicos del virus de inmunodeficiencia felina (anti-gp40) en muestras de suero y plasma.

La metodología y la interpretación de los resultados se hicieron de acuerdo con la recomendación del fabricante. Fue un estudio descriptivo completamente al azar donde se utilizó estadística de prueba. Adicionalmente, a los dueños de las mascotas se les preguntó al momento de la toma de la muestra la raza, edad, sexo, estado de vacunación actual, última desparasitación y estado reproductivo (castrado o entero).

\section{RESULTADOS Y DISCUSIÓN}

\subsection{Estimación de la prevalencia}

Según los resultados del primer censo de felinos de la ciudad de Tunja, la población de gatos domiciliados para febrero del 2018 alcanzó los 9984 animales. Aspecto que motiva para realizar exámenes de rigor para poder detectar los virus de inmunodeficiencia y leucemia felina, que han tenido una incidencia amplia en los últimos años.

A nivel mundial, se han realizado varios estudios, evaluando de esta forma, el aumento de la población felina y así, el estado infectivo de los gatos frente a la leucemia felina $\mathrm{y}$ la inmunodeficiencia. Las investigaciones realizadas demuestran diferentes porcentajes de infección, pero generalmente los valores no son muy variables, por ejemplo Little en 2011 [13] realizó un estudio en donde encontró prevalencias alrededor de $19 \%$ para FeLV.
Como es de conocerse en este estudio, una tasa del 19\% fue encontrada en animales clínicamente sanos con serología positiva para leucemia $(9 \%)$, inmunodeficiencia (9\%) o ambas (1\%) de 100 animales evaluados (tabla 1) Se ha investigado estudios en Brasil como el de Reche Jr. Et al 1997 [14], que encontraron resultados semejantes del $11.7 \%$ para el caso de inmunodeficiencia en 401 gatos domésticos de Sao Paulo. Souza et al 2002 [15] encontraron un valor del $16.6 \%$ positivos a FIV con un total de 126 animales.

Por otra parte, en comparación con lo detallado para el caso de Río de Janeiro y la zona fluminense, la ocurrencia de la infección de Leucemia en gatos fue del 11,52 \% (126 gatos de 1094) [16, 17]. Para el caso de FIV, en Chile, se evaluaron 321 muestras de sangre de gatos, encontrándose un $15,58 \%$ de prevalencia [18], en otros países como Japón con un 28,9\% [22], Francia con un 19,6\% [23] y Estados Unidos con un $14 \%$ [24]. De igual forma, se tienen estudios en otros países como Chile, donde se testaron 321 gatos, en el resultado se encuentra que el $19,94 \%$ correspondieron a gatos positivos a FeLV [18], en otros países como Italia, se evidencia un porcentaje del 18\% [19], en Grecia un 15\% [20] y algunos países como Vietnam del Norte y del Sur [21] con un $0 \%$, respectivamente.

A través de la prueba SNAP combo FeLV Ag/ FIV $\mathrm{Ab}$, se logró obtener una seroprevalencia del $9 \%$ para leucemia felina, del $9 \%$ para inmunodeficiencia felina y doble infección fue del 1\% (tabla 1); en gatos evaluados en la clínica Gattos en la ciudad de Tunja. Un estudio realizado en la ciudad de Montería permitió establecer una prevalencia para FeLV del 23,3\% (14/60), para FIV del 1,6\% (1/60) y para doble infección del $5 \%(3 / 60)$ en gatos domésticos sanos [25]; un estudio realizado en el sur del valle de aburra reporta una frecuencia del 10,7\% (128/184) para FIV [26] y finalmente un estudio realizado en la ciudad de Bogotá reporta un seroprevalencia para FIV 13.1\% (53/403), para FeLV de 11.4\% (46/403) y doble infección de 2.7\% (11/403) [27]. Al comparar la prevalencia de FIV y FeLV del presente estudio con investigaciones realizadas en el país, se observa que los resultados obtenidos en este estudio se encuentran por debajo de los hallazgos en las ciudades mencionadas anteriormente. 


\subsection{Datos epidemiológicos}

De acuerdo a algunos estudios, Little [13], se pudo observar que el riesgo para la infección de inmunodeficiencia era 3,43 veces mayor en animales que tenían acceso a la calle y de igual forma el contacto con el ambiente externo aumenta el chance de infección por el virus en un $4,3 \%$ de incidencia [10]. Teniendo presente lo anterior, se comprueba para este estudio, que la mayoría de animales con FIV tenían acceso a ambiente externos o fueron adoptados de la calle.

De los 100 gatos, 62 fueron hembras y 38 machos; los animales se encontraban en un rango de edad entre 7 meses y 5 años (con una media de 1.5 años). La procedencia de los gatos fue de la ciudad de Tunja atendidos en la clínica veterinaria Gattos. Los gatos seropositivos al FeLV fueron 7 hembras y 2 machos, al FIV fueron positivas 6 hembras y 3 machos, con infección doble 1 macho, para un total de 19 animales seropositivos (Tabla 1).

Tabla 1. Seroprevalencia del virus de leucemia e inmunodeficiencia felina en la clínica Gattos en la ciudad de Tunja.

\begin{tabular}{lcccc}
\hline Sexo & \multicolumn{2}{c}{ Infección } & Doble & Seronegativos \\
& FIV & FeLV & FIV-FeLV & \\
\hline Hembras & 6 & 7 & 0 & 49 \\
Machos & 3 & 2 & 1 & 32 \\
Total & $9(9 \%)$ & $9(9 \%)$ & $1(1 \%)$ & 100 \\
\hline
\end{tabular}

\subsection{Examen clínico}

En el examen realizado a los pacientes del estudio se encontró que ninguno de ellos presentaba ningún signo relacionado a estas enfermedades.

\subsection{Raza}

Los gatos común Europeo tuvieron la totalidad en la incidencia en presentar los virus de FIV y VeLF con el 17\% frente a otras razas también evaluadas como el siamés 1\% Sagrado de Birmania, American Shorthair, Scottish Fold y el Persa, estos últimos no fueron positivos a ninguno de estos virus. En cuanto a los animales con coinfección solo se encontró el 1\% el cual corresponde a un gato común europeo, mientras que ninguno de los gatos de raza presentó coinfección; la presentación del virus en gatos común europeo puede deberse principalmente a que es la población más frecuente que acude a consulta y que aquellos gatos de raza son comprados en criaderos donde garantizan que son libres de enfermedades infecciosas (Tabla 2).
De igual forma, un estudio realizado por Collazos [27], en la ciudad de Bogotá reporta un porcentaje mayor en la presentación del virus en gatos común europeo de $(94,2 \%)$ mientras que en gatos de raza fue tan solo el $5,7 \%$, lo que coinciden con los resultados obtenidos en este estudio.

Por otra parte, la raza no es un factor predisponente del virus, se puede observar que para el estudio del Valle de Aburrá [26], los gatos sin raza definida mostraron una frecuencia de FIV del $82,6 \%$, seguido de la raza persa con un $6 \%$ y siamés con un $4,3 \%$. De igual forma, según Collazos [27], los gatos mestizos presentaron un mayor porcentaje de infección frente a FIV y FeLV con respecto a los gatos de raza. En cuanto a los gatos coinfectados tuvieron un predominio los gatos mestizos en donde ninguno de los gatos de raza, presentó coinfección en la ciudad de Bogotá.

Lo anterior, se basa en que la población de gatos más abundante para la zona es la mestiza $\mathrm{y}$ de igual forma, muchos animales son de origen desconocido como el caso del presente estudio. 
Tabla 2. Razas de gatos encontradas en el estudio de seroprevalencia del virus de leucemia e inmunodeficiencia felina en la clínica Gattos en la ciudad de Tunja.

\begin{tabular}{lccc}
\hline \multicolumn{1}{c}{ Raza } & Total de Felinos & Positivos & \% \\
\hline Sagrado de Birmania & 1 & 0 & 0 \\
\cline { 2 - 4 } American Shorthair & 1 & 0 & 0 \\
Scottish Fold & 1 & 0 & 0 \\
Exótico & 1 & 0 & 0 \\
Persa & 6 & 0 & 0 \\
Siamés & 2 & 1 & 1 \\
Común Europeo & 88 & 18 & 100 \\
Total & 100 & 19 & 100 \\
\hline
\end{tabular}

\subsection{Estado reproductivo}

En cuanto a la prevalencia de acuerdo al sexo para el caso de inmunodeficiencia a nivel Internacional, países como Brasil, se encontró que un estudio de Belo Horizonte [28], el sexo no fue considerado un factor estadísticamente significativo pero el estudio de Souza [15] encuentran una predisposición en los machos; lo anterior, concuerda de igual forma, con el estudio realizado en Sao Paulo [14], donde el 75\% de los gatos positivos a FIV eran machos.

Investigaciones de otros países de Suramérica, por ejemplo, en Chile [18], donde se evaluaron 321 muestras de sangre de gato, de las hembras positivas a FeLV, fue de un $14,29 \%$ en las enteras y un $15,94 \%$ en las esterilizadas. En los machos, se encontró, un $22,7 \%$ positivos a FeLV para los castrados y $19,48 \%$ de machos con leucemia sin castrar.

Para el caso de Inmunodeficiencia, en el mismo estudio de Chile [18], se pudo observar que $5,71 \%$ de hembras enteras resultaron positivas en comparación con $8,7 \%$ de las esterilizadas. En los machos, la diferencia fue muy leve, mostrando que los enteros tuvieron un porcentaje del $25,97 \%$ y los castrados 25\%; Por consiguiente y comparando con el estudio realizado en Tunja, el sexo no fue un factor desencadenante de la enfermedad.
Algunos estudios del país, como por ejemplo, el realizado en la ciudad de Bogotá [27], el género tuvo una significancia estadística para los gatos infectados por FIV y FeLV en donde los machos, presentaron mayor infección que las hembras, en cuanto a los animales con infección, el género que más sobresale son los machos.

Otras investigaciones, como la realizada por Tique [25] en la ciudad de Montería, los hallazgos para el estado reproductivo de los gatos indica que las hembras, siete se encontraban preñadas, dos esterilizadas y 17 enteras y para los machos, dos castrados y 26 enteros. De lo anterior, los machos presentaron mayor seropositividad que las hembras.

Se debe tener presente, que como en este estudio, no tiene mayor relevancia el sexo para la enfermedad, como ocurre en el estudio del Valle de Aburrá [26], donde se evidencia que en cuanto al género no se encontraron diferencias estadísticas, lo que indica que existe una proporción similar de la presencia de la enfermedad entre machos y hembras.

En cuanto al estado reproductivo del estudio realizado en la ciudad de Tunja, en la clínica Veterinaria Gattos, se encontró que de las 62 hembras 22 se encontraban estériles y 38 machos de los cuales 16 se encontraban castrados (Tabla $3)$. 
Delia Yuliana Massey-Malagón et. al.

Tabla 3. Estado reproductivo de los gatos estudiados en la clínica Gattos en la ciudad de Tunja.

\begin{tabular}{ccc}
\hline Sexo & Castrados & Enteros \\
\hline Hembra & 22 & 40 \\
Macho & 16 & 22 \\
Total & 38 & 62 \\
\hline
\end{tabular}

\section{DISCUSIÓN}

Son pocos los estudios realizados respecto al tema en el país, por lo anterior, se hace necesario investigar sobre la incidencia de la enfermedad en varias regiones ya que la población de gatos en Colombia ha ido aumentando considerablemente y este tipo de enfermedades virales está afectando con mayor frecuencia a la población felina y si se descubre a tiempo, se puede realizar un manejo clínico efectivo.

De igual forma, se sugiere realizar estudios donde se evalué el estado de infección de los gatos de la ciudad más grande en donde se tome un numero de muestra más significativo que el realizado en la clínica Gattos y con ello tener una mejor perspectiva de cómo se encuentra la ciudad de Tunja en cuanto a estas enfermedades ya que el presente estudio es el primero que se hace hasta el momento.

Por otra parte, los resultados obtenidos, muestran que cada vez es más importante el diagnóstico precoz, es decir, testar a los gatos para este tipo de enfermedades antes de la introducción al ambiente con otros animales y la implementación de medidas de prevención de FeLV y FIV, lo anterior, contribuye a la disminución de estos virus en la población felina.

\section{CONCLUSIONES}

La inidencia de los virus de inmunodeficiencia y leucemia felina viene aumentando cada día más en la ciudad de Tunja, aspecto que genera una alarmante preocupación en el poder contar con felinos sanos y poder tomar las medidas adecuadas en el poder controlar y realizar exámenes preventivos que generen un mejor bienestar para la especie.
Es de vital importancia que se realice el test para poder detectar estos de tipo de virus y que los felinos infectados tengan el tratamiento adecuado al igual que el manejo y se le pueda generar un estilo de vida acorde a la enfermedad.

\section{BIBLIOGRAFÍA}

[1] F. Alves, D. S. Rajao, H. L. Del Puerto, G. F. Braz, R. C. Leite, C. Mazur, A. S. Martins y J. K. Reis, «Occurrence of feline immunodeficiency virus and feline leukemia virus infection in cats,» Am. J. Anim. Vet. Sci, no 6, pp. 125-129, 2011.

[2] O. Jarrett, «Strategies of retrovirus survival in the cat,» Vet Microbioly, n ${ }^{\circ} 69$, pp. 99107, 1999.

[3] W. F. Jarrett, E. M. Crawford y W. B. Martin, «A virus-like particle associated with leukemia (lymphosarcoma),» Nature, $n^{\circ} 202$, pp. 567-569, 1964.

[4] W. F. Jarrett, W. B. Martin y G. W. Crighton, «Transmission experiments with leukemia (lymphosarcoma),» Nature, $\mathrm{n}^{\mathrm{o}}$ 202, pp. 566-567, 1964.

[5] B. J. Willett y M. J. Hosie, «Feline leukaemia virus: half a century since its discovery,» The Veterinary Journal, vol. 195, $\mathrm{n}^{\mathrm{o}} 1$, pp. 16-23, 2013.

[6] K. Hartmann, «Infección por Virus de Leucemia Felina,» de Enfermedades Infecciosas del Perro y el Gato. Greene, C, Buenos Aires, InterMédica, 2008, pp. 116145.

[7] M. Palmeroy V. Carballes, Leucemia Felina. Inmunodeficiencia felina. Enfermedades infecciosas felinas., España: Servet, 2010. 
[8] S. E. Little, The cat - Clinical Medicine and Management, Missouri: Saunders, 2012.

[9] K. Hartmann, «Clinical aspects of feline retroviruses: A review,» Viruses, vol. 4, pp. 2684-2710, 2012.

[10] I. Lee, J. Levy, S. Gorman, P. Crawford y M. Slater, «Prevalence of feline leukemia virus infection and serum antibodies against feline immunodeficiency virus in unowned free-roaming cats.,» J. Am. Vet. Med. Assoc, vol. 220, n 5, pp. 620-622, 2002.

[11] E. Spada , D. Proverbio, A. Della Pepa, R. Perego, L. Baggiani, G. Bagnagatti, G. Domenichini , E. Ferro y F. Cremonesi, «Seroprevalence of feline immunodeficiency virus, feline leukaemia virus and Toxoplasma gondii in stray cat colonies in northern Italy and correlation with clinical and laboratory data.,» J. Feline Med, vol. 14, nº 6, pp. 369-377, 2012.

[12] A. T. Weiss, R. Klopfleisch y A. D. Gruber, «Prevalence of feline leukaemia provirus DNA in feline lymphomas,» $J$ Feline Med , vol. 12, n 12 , pp. 929-935, 2010.

[13] S. Little, "A review of feline leukemia virus and feline immunodeficiency virus seroprevalencein cats in Canada,» Veterinary Immunology and Immunopathology, vol. 143, no 3, pp. 243-245, 2011.

[14] J. Reche, «Clinical study of acquired immunodeficiency syndrome in domestic cats in São Paulo,» Braz J Vet Res Anim Sci, vol. 34, pp. 152-155, 1997.

[15] H. J. Souza, «Estudo epidemiológico de infeções pelo vírus da leucemia e/ ou imunodeficiência felina, em gatos domésticos do município do Rio de Janeiro,» Clin Vet, vol. 36, pp. 14-21, 2002.

[16] A. Arjona, E. Escolar, I. Soto, N. Barquero y D. Martin, «Seroepidemiological Survey of Infection by Feline Leukemia Virus and immunodeficiency Virus in Madrid and Correlation with Some Clinical Aspects,» Journal of Clinical Microbiology, vol. 38, $\mathrm{n}^{\circ}$ 9, pp. 3448-3449, 2000.
[17] J. Braley, «FeLV and FIV; Survey Shows Prevalence in the United States and Europe,» Feline Practice, vol. 22, n 2, pp. 25-28, 1994.

[18] P. Muñoz, Descripción epidemiológica de gatos positivos a los virus leucemia felina e inmunodeficiencia felina, Chile: Universidad de Chile, 2005.

[19] P. Bandecchi, D. Matteucci, F. Baldinotti, G. Guidi, F. Abramo, F. Tozzini y M. Bendinelli, «Prevalence of feline immunodeficiency virus and other retroviral infections in sick cats in Italy,» Vet Immunol Immunopathol, vol. 31, no 3-4, pp. 337-345, 1992.

[20] A. Koutinas y G. Koptopoulos , «Low prevalence of feline viral infections in northern Greece,» Vet.Rec, vol. 133, pp. 245-247, 1993.

[21] K. Nakamura, T. Miyazawa, Y. Ikeda, E. Sato, Y. Nishimura, N. Nguyen, E. Takahashi, M. Moshizuki y T. Mikami, «Contrastive prevalence of Feline Retrovirus infections between Northern and Southern Vietnam,» J. Vet. Med. Sci, vol. 62, no 8, pp. 921-923, 2000.

[22] T. Ishida, T. Washizu, K. Toriyave, S. Motoyoshi, I. Tomoda y N. Pedersen, «Feline immunodeficiency infection in cats of Japan,» JAVMA, vol. 194, n 2, pp. 221225, 1989.

[23] F. Courchamp, N. Yoccoz, M. Artois y D. Pontier, "At-risk individuals in Feline Immunodeficiency Virus epidemiology: evidence from a multivariate approach in a natural population of domestic cats (Felis catus),» 1998. [En línea]. Available: http://www.ncbi.nlm.nih.gov/entrez/ query. fcgi? $\mathrm{cmd}=$ Retrieve $\& \mathrm{db}=$ pubmed $\&$ dopt $=$ Abstract\&list_uids $=9747777$. [Último acceso: 15 Septiembre 2004].

[24] J. K. Yamamoto, H. Hansen, E. W. Ho, T. Morishita, T. Okuda, T. R. Sawa, R. M. Nakamura y N. C. Pedersen, «Epidemiologic and clinical aspects of feline immunodeficiency infection in cats from continental United States and Canada 
and possible mode of transmission,» JAVMA, vol. 194, nº 2, pp. 213-220, 1989.

[25] V. Tique, A. Sanchez, L. Alvarez, R. Ríos y S. Mattar, «Seroprevalencia del virus de leucemia e imunodeficiencia felina en gatos de Montería, Córdoba,» Revista de la Facultad de Medicina Veterinaria y de Zootecnia, vol. 2, no 56, pp. 85-94, 2009.

[26] V. Molina, R. Blanco, P. Estepa y S. Tamayo, «Frecuencia del Virus de Inmunodeficiencia Felina (VIF) en el Sur del Valle de Aburrá, Colombia (2013-2015).,» Revista Científica , vol. 26, nº 6, pp. 374-378, 2016.

[27] M. Collazos, Coinfección y hallazgos epidemiológicos de los virus de inmunodeficiencia felina (VIF) y leucemia felina (VILEF) en gatos clinicamente enfermos., Bogotá: Tesis de grado para optar al título de Magister en Ciencias Biológicas. Pontificia Universidad Javeriana., 2016.
[28] B. M. Teixeira, D. S. Rajão , J. P. Haddad, R. C. Leite y J. K. Reis, "Ocorrência do Vírus da Imunodeficiência Felina e do Vírus da Leucemia felina em gatos domésticos mantidos em abrigos no município de Belo Horizonte,» Arq. Bras. Med. Vet. Zootec, vol. 59, pp. 939-942, 2007.

[29]. B. Chhetri, O. Berke, D. Pearl y D. Bienzle, «Comparison of the geographical distribution of feline inmunodeficiency virus and feline leukemia virus infectios in the United States of America,» BMC Veterinary Research, vol. 9, nº 2, 2013.

[30] J. Beatty, «Viral causes of feline lymphoma: retrovirus and beyond,» Veterinary Journal , vol. 201, pp. 174-180, 2014.

[31] T. A. Vintimilla Mendez y A. R. Ordoñez Palacios, Prevalencia de Leucemia Viral Felina e Inmunodeficiencia Felina en gatos domésticos de la ciudad de Cuenca., Cuenca-Ecuador, 2014 